\title{
O VOO ENTRE A VIDA E O NADA: ANÁLISE DO POEMA “ELEGIA (I)” DE ORIDES FONTELA
}

Alexandre Bonafim FELIZARDO (USP) ${ }^{1}$

Resumo: Neste ensaio, intentamos fazer uma leitura do poema "Elegia (I)" de Orides Fontela. Para tanto, analisaremos os recursos estilísticos do texto, revelando o quanto a lírica da autora paulista possui raízes existenciais e filosóficas. Em "Elegia (I)", podemos observar uma série de antíteses, pelas quais a autora empreende uma pesquisa ontológica do mundo e da condição humana.

PALAVRAS-CHAVE: Poesia brasileira contemporânea; Orides Fontela; Existencialismo.

Abstract: In that rehearsal, we attempted to do a reading of the poem "Elegia (I)" by Orides Fontela. For this, we'll analyze the stylistic resources of the text, revealing how much author's lyrical has existential and philosophical roots. In the "Elegia (I)", we can observe a series of antitheses, for the which the author undertakes a research ontological of the world and of the human condition.

KEYWORDS: Brazilian contemporary poetry; Orides Fontela; Existentialism.

ELEGIA (I)

1. Mas para que serve o pássaro?

2. Nós o contemplamos inerte.

3. Nós o tocamos no mágico fulgor das penas.

4. De que serve o pássaro se

5. desnaturado o possuímos?

6. O que era vôo e eis

7. que é concreção letal e cor

8. paralisada, íris silente, nítido,

9. o que era infinito e eis

10. que é peso e forma, verbo fixado, lúdico

11. o que era pássaro e é

12. o objeto: jogo

13. de uma inocência que

14. o contempla e revive

15. - criança que tateia

16. no pássaro um esquema

17. de distâncias -

18. mas para que serve o pássaro?

19. O pássaro não serve. Arrítmicas

20. brandas asas repousam.

(p.131) 


\section{Uma indagação existencial}

Intentamos, nesse artigo, fazer uma análise do poema "Elegia (I)" de Orides Fontela. Para tanto, seguiremos o percurso do texto, tentando nuançar e detalhar significados subjacentes às figuras do texto.

Quando lançamos um primeiro olhar sobre o poema, chama-nos a atenção a maneira como tal texto se inicia. O leitor é abruptamente arrancado do silêncio que antecede à leitura, a fim de vivenciar a tensão de um questionamento que o toma de surpresa: "Mas para que serve o pássaro?”. Diante de tal pergunta, o leitor é posto em uma situação conflitante, em uma situação que passa a lhe exigir todo o envolvimento, como se ele tivesse a resposta para esse enigma. Assim, quem lê permanece, logo após esse primeiro verso, em suspenso, como que diante do próprio mistério. Isso se dá devido à proximidade que o eu lírico exige do leitor, como se esse fosse uma espécie de testemunha, cúmplice de um mesmo espanto, de uma mesma revelação, ou seja, a visão inesperada de um pássaro morto.

O ritmo do poema privilegia, portanto, o choque abrupto propiciado pela indagação. O texto inicia-se numa espécie de ápice, em que o leitor sai de uma situação de repouso, a fim de vivenciar, de maneira inesperada, o momento culminante de um enigma.

Portanto, em "Elegia (I)", o espaço branco que sucede ao primeiro verso toma significação, ele passa a ser o vácuo, o silêncio que circunda o mistério de uma resposta enigmática. A postura do eu lírico, no segundo verso, enfatiza ainda mais essa ruptura típica da versificação, uma vez que ele permanece impassível, indiferente a uma possível resposta à sua indagação: "Nós o contemplamos inerte". Isso só faz aumentar a dramaticidade que compõe o silêncio que se segue à pergunta. Tal efeito leva o leitor a sentir necessidade de empreender uma reflexão, haja vista que o ato reflexivo sempre vem associado ao questionamento. Entretanto, o ritmo do poema o leva ao segundo verso, deixando a pergunta em suspenso, realçando-se ainda mais o seu ar de mistério. A partir daí, o sujeito lírico toma uma atitude imprevista, ele imobiliza-se pela surpresa, conclamando o leitor à mesma atitude. O pronome "nós" só intensifica a cumplicidade que, a partir de então, torna-se patente, entre o leitor e o eu lírico. Tal pronome põe 
aquele que lê na mesma arena onde se posiciona o sujeito lírico. É como se o leitor passasse a ver também o pássaro, do mesmo lugar e nas mesmas condições do eu poético.

É importante observar o poder semântico que a frase interrogativa ganha no contexto do poema. Interrogar é, antes de tudo, constatar-se enquanto ser pensante, enquanto ser existencialmente presente no mundo. O questionamento é uma atividade mental que, ao voltar-se para a realidade objetiva, ilumina a existência da consciência desse ser indagador. Questionar a realidade, portanto, é um exercício reflexivo que revela a presença do sujeito no mundo. Ao questionar o mundo, o sujeito toma consciência de si e, por sua vez, apreende a sua condição existencial. Augras (1986, p.20) chama a atenção para a realidade ontológica do homem: “O homem é testemunha da realidade do mundo". Ter consciência do mundo é ter consciência de si. Perceber o objeto é perceber a si mesmo, tal como nos afirma Augras: a "percepção do mundo estabelece a coexistência do sujeito e do objeto, na sua interdependência. A consciência do objeto é também a consciência de si. A percepção do objeto pelo sujeito é parte integrante desse objeto" (AUGRAS, 1986, p.20).

Portanto, quando o eu lírico percebe o pássaro, ele também se percebe, quando ele indaga sobre aquele objeto surpreendente que se desvela ao olhar, ele passa a perceber a própria consciência. Assim, o pássaro transforma-se numa espécie de correlato objetivo do eu lírico. O olhar perplexo do eu poético encontra-se espelhado no pássaro. Esse, por sua vez, está marcado por características que registram essa presença do eu no mundo: "mágico fulgor". A surpresa do ser, para lembrar Heidegger, está expressa nessa qualificação que o sujeito faz em relação às penas (metonímia para pássaro). Caracterizar um objeto é, na verdade, expressar a presença de uma subjetividade. Por outro lado, isso é próprio da natureza da disposição lírica, que percebe o mundo estando nele. Staiger (1972, p.59) afirma que a percepção lírica nos coloca "maravilhosamente 'fora', não diante das coisas mas nelas e elas em nós".

Todavia, é importante salientar que, apesar de o pássaro refletir a subjetividade do eu poético, a cisão entre o objeto e o sujeito é mantida. Inclusive é essa distância do ser poético em relação ao pássaro que proporciona a tensão da pergunta, pois o sujeito 
permanece pasmado ante aquela visão, como se ele se deparasse com um objeto sobrenatural. O reconhecimento do mundo faz-se através do reconhecimento do sujeito como um ser autônomo em relação ao objeto, num conflito entre a intimidade do observador e a realidade circundante.

Esse conflito, entretanto, não deve ser visto como algo nocivo, pois ele instaura o novo, ele possibilita a re-criação do mundo pelo sujeito, processo inerente da própria vida. Portanto, o pássaro serve ao sujeito lírico como objeto de conhecimento e sondagem do mundo. $\mathrm{O}$ eu lírico, ao fitar o pássaro, percebe-se como ser ontologicamente presente em um espaço, um ser que vivencia, através do olhar, sua condição existencial.

Há, na verdade, um paralelismo entre o pássaro e o eu lírico. Tanto o eu observador quanto o pássaro encontram-se estáticos: "Nós o contemplamos inerte./ Nós o tocamos no mágico fulgor das penas". Ambos permanecem em estado de repouso, completamente paralisados. O pássaro é "concreção letal", ser que, devido a sua atual condição, ou seja, devido ao fato de estar morto, tornou-se, evidentemente, paralisado, tal como o eu que se encontra petrificado pelo espanto, em estado de transe ante àquela aparição. Todavia, pode-se perceber, nesse paralelismo, um antagonismo que delimita tanto o sujeito quanto o objeto. O sujeito encontra-se pulsante, vivo, ao passo que o pássaro está morto. Morte e vida, contraste que, paradoxalmente, acentua o paralelismo.

Esse paralelismo intensifica a vivência existencial do eu poético que, através daquela aparição da ave morta, passa a se ver no mundo, situando-se em um espaço que lhe é existencialmente estranho. O sujeito lírico, então, busca compreender o universo e a sua condição, utilizando, para isso, aquela presença ao mesmo tempo sedutora e sobrenatural. 


\section{A morte estranha}

No terceiro verso, o eu lírico, ao utilizar o verbo "tocar", expressa uma aproximação mais consistente em relação ao pássaro. Se, no segundo verso, o sujeito poético aprazia-se apenas com a contemplação do objeto, agora, o envolvimento tornase mais intenso, corporal. O paralelismo sintático que há entre os dois versos coloca numa mesma posição os verbos contemplar e tocar. Tal recurso revela a demasiada curiosidade do eu poético que, para constatar aquele fato surpreendente, ou seja, a presença do pássaro morto, passa a sentir a necessidade não só de contemplá-lo, mas, principalmente, de tocá-lo, de apalpá-lo, a fim de que a razão possa assimilar a morte como um fato natural na ordem do mundo.

Nos dois últimos versos da primeira estrofe, temos novamente a presença da pergunta que abre o texto. Todavia, com uma diferença semântica e sintática, pois a pergunta vem acrescida de outra oração: "se/ desnaturado o possuímos?". A pergunta retorna, não só nesse instante, mas ao longo de todo o poema, numa articulação do plano da expressão que visa a reforçar a idéia de surpresa do sujeito lírico ante a visão mágica do pássaro. $\mathrm{O}$ ato de repetir uma mesma pergunta revela o pasmo, o olhar atônito ante um mistério indeslindável. Nesse sentido, o olhar focaliza a morte do pássaro com um profundo sentimento de surpresa ante a efemeridade da vida.

Esse olhar constrito, por sua vez, relaciona-se com a postura do homem moderno ante a finitude da vida. A morte em nossa sociedade burguesa foi posta à margem, foi banida da realidade cotidiana. Arrigucci Júnior (1999, p.224), ao analisar o poema "Profundamente" de Bandeira, chama a atenção para o texto de Benjamin, no qual esse autor empreende uma reflexão sobre o banimento da morte no espaço da vida burguesa. Com o fim do trabalho artesão e o advento do produto industrializado, o homem perdeu a noção de eternidade que se relaciona com o lento trabalho artesanal. Com isso ele deixou de vivenciar o sentimento do eterno que se interliga à própria noção de morte. Desabituada da presença da morte, a sociedade burguesa enche-se de horror e pasmo quando, inevitavelmente, a morte irrompe em meio à vida com toda a sua carga de verdade e desilusão. Esse horror leva essa sociedade a colocar à margem tudo o que indica a presença da doença e da morte: "os burgueses vivem em espaços depurados de 
qualquer morte e, quando chegar sua hora, serão depositados por seus herdeiros em sanatórios e hospitais" (BENJAMIN, 1987, p.207). A necessidade neurótica de higiene e ordem levou o burguês a uma cegueira ante a sua própria condição. Isso só acentuou a estranheza com a qual o homem moderno se depara diante da finitude humana. Benjamin (1987, p.207) elucida, com clareza, esse não que o burguês diz ao espetáculo da morte:

No decorrer dos últimos séculos, pode-se observar que a idéia da morte vem perdendo, na consciência coletiva, sua onipresença e sua força de evocação. Esse processo se acelera em suas últimas etapas. Durante o século XIX, a sociedade burguesa produziu, com as instituições higiênicas e sociais, privadas e públicas, um efeito colateral que inconscientemente talvez tivesse sido seu objetivo principal: permitir aos homens evitarem o espetáculo da morte.

A morte na sociedade burguesa, portanto, é acompanhada por um olhar de estranheza e inconformismo.

Com efeito, pode-se perceber, no poema de Fontela, esse mesmo movimento de não aceitação da finitude, em que a reiteração, também redundante, da pergunta "Mas para que serve o pássaro?", ilustra todo o constrangimento do homem moderno ante finitude da vida.

\section{3. $\mathrm{O}$ vôo rumo à morte}

A partir da segunda estrofe, inicia-se no poema um jogo de tensões, em que características contraditórias passam a ser relacionadas ao pássaro. Também a partir do sexto verso, o paralelismo sintático torna-se mais ostensivo, estendendo-se até o décimo segundo verso. Esses versos são estruturados, sintaticamente, numa mesma forma que sempre marca uma mudança temporal. Eles nos remetem, através do pretérito imperfeito do verbo ser, a um passado em que o pássaro vivenciava uma determinada circunstância. Logo após a enunciação desse passado, passa-se a privilegiar, no texto, o presente. Esse momento do agora, instante vivo captado pelo eu lírico, é aquele em que o olhar capta a visão do pássaro inerte e que faz um contraponto ao pretérito. Com essa reincisão de estruturas que formam o paralelismo, o discurso irá marcar um constante retorno, um ir e vir que pontuará o ritmo. De acordo com Cohen (1974, p.47), todo 
"verso é 'versus', ou seja, retorno", estrutura essa que faz "oposição à prosa ('prosus') que avança linearmente". Para o autor, "o verso volta sempre sobre si mesmo. Gerard Hopkins dá-lhe a seguinte definição, conservada por Jakobson: 'discurso que repete total ou parcialmente a mesma figura fônica"”.

Essa falta de progressão do discurso, ocasionada pelo paralelismo e pela própria natureza do verso, que sempre regressa sobre si mesmo, imprimirá um ritmo ao poema que tende ao repouso, como se o texto formasse um quadro, um momento congelado no tempo. O constante retorno dessas estruturas sintáticas, às quais se pode incluir a constante aparição do questionamento que abre o texto, refaz o olhar do sujeito poético, como se ele emoldurasse o pássaro em uma tela, realçando-lhe os atributos pictóricos e físicos. Cada retorno do verso corresponde a uma fixação do olhar, olhar estático que se deixa irradiar pelo assombro ante aquela imagem ao mesmo tempo cotidiana e surpreendente. Portanto, o ritmo do poema, pontuado pela reincisão das estruturas, acompanha a trajetória do olhar pasmado, revelando-lhe a fixa atenção, a estática concentração.

Convém, agora, analisar cada uma das oposições que se delineiam a partir do sexto verso, registrando, assim, as nuanças semânticas que as diferenciam. O primeiro conjunto estabelece uma oposição entre o movimento ("O que era vôo...") e a estaticidade ("e eis/ que é concreção letal e cor/ paralisada..."). A dialética dá-se, portanto, entre o "vôo" e a "paralisia".

Essa oposição, na verdade, relaciona-se com aquela de cunho mais profundo à qual se liga o título do poema, "Elegia (I)". De acordo com Moisés ([s.d.], p.167), esse tipo de poesia originou-se de cantos fúnebres, cantos que revelavam o sofrimento ante a finitude humana. Portanto, com base na afirmação desse importante crítico, pode-se afirmar que a dialética entre o movimento e a estaticidade revela, no poema de Fontela, a oposição entre a vida e a morte. Os outros movimentos paralelísticos que se seguirão, na verdade acompanharão essa passagem da vida (vôo) para a morte (repouso). A vida, em sua força plena, é desejo, é volúpia, é movimento constante, ao passo que a morte é o fim da pulsação, é a paralisia daquilo que antes vibrava. 
Novamente, tem-se, portanto, a presença daquele olhar atônito ante a contingência e a caducidade inerentes à condição humana. Augras (1986, p.22), com base na obra de Heidegger, afirma que só o homem possui a consciência de sua finitude. O homem é o ser do projeto, ele sempre constrói a sua vida no futuro. Entretanto, quanto mais ele se percebe em um tempo vindouro, mais ele se aproxima do limite que marca a vida humana, ou seja, a morte: "Na lonjura desponta a morte. O ser do projeto é apenas, irremediavelmente, o ser para a morte. A morte que denuncia a possibilidade dos possíveis.”. É essa consciência da finitude humana que marca o olhar do eu lírico que, uma vez fixando sua atenção no pássaro, desvela a verdade do homem, a sua natureza precária. Olhar o pássaro é descobrir a fragilidade do instante, é sentir com toda a força a fugacidade daquele momento.

É importante notar que toda a obra de Fontela é marcada por uma aguda consciência dos limites da condição humana. Em inúmeros poemas, a autora de Trevo revela uma lucidez extremada ante o tempo e o ser do homem:

$[\ldots]$

consciência demais do ser (FONTELA, 1988, p.31).

$[\ldots]$

A vida é lúcida e impossível (FONTELA, 1988, p.35).

$[\ldots]$

E enquanto sofremos

a hora intensa

lentamente o tempo

perde-nos.

(FONTELA, 1988, p.130)

Arrigucci Júnior (apud BUCIOLI, 2004, p.44), inclusive, afirma que essa "lucidez cortante" é uma das características mais "poderosas" da poesia de Fontela. Como já se afirmou, a elegia possui como origem os cantos fúnebres, os cantos que tinham como tema a morte. Arrigucci chama a atenção para as forças rítmicas que compõem a elegia. De acordo com o estudioso da obra bandeiriana, o ritmo elegíaco, de forte musicalidade, propicia o entorpecimento da consciência diante da morte. Como a cantiga de ninar que embala a criança levando-a a dormir, a elegia possuiria uma força 
hipnótica capaz de apaziguar o medo da morte. Assim, a elegia é "como uma tentativa mágica para apaziguar um espírito sem repouso, ou seja, como um meio mágico de proteção contra a ansiedade mais funda trazida pela ameaça da morte" (ARRIGUCCI, 1999, p.221).

O ritmo da elegia tem como base recursos fônicos da linguagem: assonâncias, aliterações, paronomásias, ecos, rimas, paralelismo sintático, onomatopéias e etc. Esses recursos é que propiciariam essa ilusão de entorpecimento capaz de atenuar a angústia da morte. No poema de Fontela, a constante reincisão de estruturas sintáticas que, como já foi visto, propicia uma falta de progressão ao discurso, funciona como uma espécie de pêndulo, em um constante ir e vir capaz de apaziguar tanto o eu poético quanto o leitor da angústia causada pelo sentimento da fugacidade da existência.

É justamente no oitavo verso, fragmento em que se dá a dialética entre o repouso e o movimento, que se tem o instante mais sonoro do poema: as assonâncias da vogal "i” e "a" e as aliterações das sibilantes contribuem para a formação desse ritmo elegíaco: “cor/ paralISada, ÍrIS SIlente, nÍtIdo,”. Todos esses recursos formam essa cadência que, semanticamente, liga-se às origens musicais da elegia, em que o canto servia como catarse dos sofrimentos ocasionados pela morte. Também aqui, o ritmo funciona como fonte de alento ante as dores causadas pela efemeridade da existência humana.

Nessa dialética entre o vôo e a paralisia, percebe-se, por outro lado, uma verticalidade que transpassa o poema. Dessa maneira, tem-se a vida ligada à noção de vôo, de altura, ao passo que a morte é relacionada à idéia de estaticidade, ou melhor, de pouso. Do passado recente em que se deu o vôo, expresso pelo pretérito imperfeito do verbo ser, ao agora do pássaro morto captado pelo olhar do eu poético, percebe-se um movimento de queda, de descida. Esse movimento, por sua vez, possui raiz mitológica. Para constatarmos tal registro mítico, basta lembrar o mito de Ícaro (HAMILTON, 1992, p.200-201), em que a descida relaciona-se com a dissolução do ser, com a morte. Para o jovem filho de Dédalo, o azul e o infinito são imagens de pureza que representam o desejo, a vida em sua intensidade máxima. Quando Ícaro recebe do pai as asas que o libertariam do labirinto em que se encontrava confinado, o jovem desobedece aos 
conselhos de Dédalo e parte rumo ao sol. Ao alcançar as alturas, o calor do astro dissolve-lhe as asas, levando Ícaro para o fundo das águas. A ousadia de voar em direção à luz, ao sol, por outro lado, traz o próprio reverso da liberdade, ou seja, a queda, a destruição. Esse existencialismo de fundo mítico transpassa o poema de Fontela, uma vez que o pássaro em movimento é a vida em seu êxtase total, em seu vigor absoluto, ao passo que a morte é a descida, é o esfacelamento do ser voante na realidade maciça do chão.

\section{4. $O$ infinito contingente}

Na estrutura sintática seguinte (nono e décimo versos), dando prosseguimento ao paralelismo, tem-se a dialética entre o infinito e o contingente, entre o incomensurável e o ínfimo: "o que era infinito" em oposição ao "peso", à delimitação da "forma”.

Bachelard, em sua obra $O$ ar e os sonhos (2001), revela a ligação íntima que há entre o corpo do pássaro e a imensidão do cosmos. Para o filósofo francês, o voo de um pássaro representa uma expansão desse ser voante em direção ao infinito. No voo, o pássaro contém o universo e o universo, por sua vez, contém o pássaro. $\mathrm{Na}$ própria imagem onírica do voo já se tem delineada a dialética entre o infinitamente grande e o infinitamente pequeno. Afirma o crítico temático: "no reino de uma imaginação criadora aérea, o corpo do pássaro é feito do ar que o cerca, e a sua vida do movimento que o arrebata." (BACHELARD, 2001, p. 69), ou seja, o pássaro é o ar encarnado, é o cosmos circundante que se fez sangue e pulsação. Podemos perceber a presença dessa dialética no poema "Elegia (I)" em que o voo é nomeado pelo infinito. A poeta deTrevo (1988) utiliza, nesse poema, a imagem do pássaro com o intuito de abarcar o espaço, com a intenção de sentir a grandeza do universo. O pássaro, assim, passa a conter o universo todo em si, enquanto o cosmos todo se transforma em vôo. Afirma o pensador francês: "a asa imaginária se matiza com as cores do céu" e o céu torna-se "um mundo de asas." (BACHELARD, 2001, p.74). Bachelard, portanto, liga a imensidão (céu) ao que é pequeno

Para melhor compreender a dialética entre o grande e o pequeno, convém observar como isso acontece em um texto de outro grande autor. No poema "Eu vi uma rosa" de Bandeira, há a presença de uma flor que, de acordo com Paes, expressa a dimensão do 
mundo todo em si. Transcrevemos o poema de Bandeira, com o intuito de melhor elucidar a natureza infinita dessa rosa, natureza essa tão semelhante a do pássaro presente no poema de Fontela:

Eu vi uma rosa

- Uma rosa branca -

Sozinha no galho.

No galho? Sozinha

No jardim, na rua.

Sozinha no mundo.

Em torno, no entanto,

Ao sol do meio-dia,

Toda a natureza

Em formas e cores

E sons esplendia.

Tudo isso era excesso.

A graça essencial, Mistério inefável

- Sobrenatural -

Da vida e do mundo,

Estava ali na rosa

Sozinha no galho.

Sozinha no tempo.

Tão pura e modesta,

Tão perto do chão,

Tão longe da glória

Da mística altura,

Dir-se-ia que ouvisse

Do arcanjo invisível

As palavras santas

De outra Anunciação.

(BANDEIRA, [s.d.], p.186)

A rosa do poema de Bandeira encerra o imensamente pequeno em sua circularidade, simbolizando o círculo infinito do espaço que a cerca. A flor bandeiriana é captada por um olhar que expressa uma espécie de arroubo, olhar extático e inaugural que flagra o ser da rosa em sua profundidade. De acordo com Paes, a rosa de Bandeira 
torna-se uma imago mundi, um Aleph borgiano em uma concentração do olhar poético que focaliza o mundo na pequenez daquelas pétalas:

A visão poética isola aqui um pormenor do mundo para o rever com uma intensidade tal que nele se engolfa por inteiro, esquecida da natureza circundante, agora excessiva ante a plenitude da rosa. É como se ela estivesse sendo vista pela primeira vez, e ao renomeá-la com os inéditos atributos de que ora se reveste ("graça essencial", "mistério inefável") - o poeta a transforma numa imago mundi, num Aleph borgiano cuja pequenez ("modesta", "perto do chão") é o próprio penhor de sua enormidade ("longe", "altura", "glória") [...] (PAES, 1997, p.31).

O mesmo efeito alcançado por Bandeira em seu poema, em que a rosa passa a representar, hiperbolicamente, o universo, pode-se perceber no símbolo do pássaro presente no poema de Orides. O pássaro é recortado do seu habitat, do mundo que o cerca, a fim de expressar uma dimensão que o ultrapassa. Assim, para esse ser voante, também a natureza torna-se excesso ("Tudo isso era excesso"). Posto numa espécie de foco concentrado do olhar poético, o corpo da ave, circular como o da rosa, paradoxalmente passa a expressar o infinito, o que não se pode mensurar. Tanto o pássaro quanto a rosa se transformam em um Aleph borgiano. Borges, em seu conto "O Aleph”, expressa com maestria essa dialética entre o ínfimo e o infinito. A protagonista do conto, ao descer a um sótão, depara-se com uma esfera extremamente pequena que, no entanto, revela a grandiosidade do universo. Tomada por uma iluminação, a personagem borgiana passa a contemplar todo o planeta no diâmetro daquele objeto pequeno. Eis como a personagem descreve essa experiência:

O diâmetro do Aleph seria de dois ou três centímetros, mas o espaço cósmico estava aí, sem diminuição de tamanho. Cada coisa [...] era infinitas coisas, porque eu a via claramente de todos os pontos do universo. Vi o populoso mar, vi a aurora e a tarde, vi as multidões da América, vi uma prateada teia de aranha no centro de uma negra pirâmide, vi um labirinto roto (era Londres), vi intermináveis olhos próximos perscrutando-me como num espelho, vi todos os espelhos do planeta e nenhum me refletiu [...] (BORGES, 1998, p.136).

A iluminada inspiração de Paes soube buscar com precisão essa referência do escritor argentino, interligando com maestria a rosa de Bandeira ao Aleph borgiano. Assim, a partir dessa analogia empreendida pelo poeta paulista, pode-se também 
compreender, com maior lucidez, a natureza do símbolo do pássaro presente no poema de Fontela.

Por outro lado, se o pássaro foi infinito em um passado, ele no agora é "peso" e "forma" apenas. Novamente a degradação da morte é revelada, pois é pela morte que o infinito sofre uma transmutação, tornando-se contingente. Essa exploração do espaço infinito que a poeta realiza através da imagem do pássaro só faz revelar a fragilidade inerente a esse ser e, por sua vez, ao ser do homem. A condição humana, assim como a natureza precária do pássaro, é frágil e limitada. O corpo humano, em sua extrema pequenez, trava uma luta feroz com o espaço sem fim. Diante do incomensurável, o homem toma as medidas de seu ser, ele descobre-se parcela ínfima de um cosmos interminável.

\section{O pássaro entre o ser e a inexistência}

A terceira e última estrutura sintática que compõe o paralelismo dá-se agora no âmbito da própria natureza do ser do pássaro. De ordem profunda, a dialética agora é entre o ser e o não ser: “[...] o que era pássaro e é/ o objeto”. O pássaro morto sofre, no poema, uma metamorfose tal, a ponto de toda a sua essência tornar-se degradada, inexistente. Por possuir natureza tão importante, tal dialética está na raiz das outras duas anteriores. É a contradição entre o ser e o nada a base das outras transformações. Para marcar a importância desse movimento dialético, a autora, inclusive, separou-o dos demais, incluindo-o em outra estrofe. Assim, na terceira estrofe o substantivo "pássaro" é contraposto ao substantivo "objeto" que, em sua significação, indica justamente a indiferenciação de algo no mundo. O pássaro ao transformar-se em mero objeto dissolve-se no seio da natureza, transmutando-se em matéria indefinida, matéria que se fragmenta para retornar ao todo, ao cosmos. Mero objeto sem valor, o pássaro torna-se apenas peça de um jogo. A aguda consciência do sujeito poético revela, portanto, a desconstrução daquele ser.

Com essa oposição entre o ser e não ser, finaliza-se o jogo paralelístico, em que se desvelam, através da imagem do pássaro, as três dimensões relacionadas à existência humana. A primeira liga-se ao movimento, a segunda ao espaço e a terceira relaciona-se com a essência mesma do homem enquanto ser existencialmente consciente de sua 
finitude. Todas essas dimensões (movimento, espaço e ser) revelam o humano em sua nudez total, em sua fragilidade mais intensa e verdadeira.

\section{O pássaro desconstruído}

O pássaro torna-se objeto de um jogo, de uma trama em que a destruição e o desfazer são atividades de suma importância para o eu lírico. Aliás, o destecer e o desconstruir são práticas tão essenciais à lírica de Fontela, que elas passam a ser um fundamento desse fazer poético. Bucioli, importante estudiosa da obra orideana, salienta, com primazia, em seu livro Entretecer e tramar uma teia poética (2003), a grande força que o manejo desse destecer possui na poesia da autora de Trevo (1988). Conforme expressa a autora, "Orides arrisca-se à escrita como ato de desconstrução, artifício poético por meio do qual ousa edificar a base de sua composição lírica" (BUCIOLI, 2003, p.48). A dissolução dos objetos torna-se, paradoxalmente, motivo para a construção poética de Fontela. A seleção lexical arquitetada pela poeta gravita, muitas vezes, em torno de palavras que dissolvem o ato de construção. Bucioli soube expressar com precisão esse processo, eis o que a pesquisadora afirma sobre os poemas de Fontela:

São poemas que, ao falar do ato criativo, versam sobre o movimento da desconstrução. Predomina o uso dos prefixos, em especial os negativos (des), e abundam os verbos a traduzir o "desfazimento" proposto pelo "eu". Neste sentido, aparecem destrançar ("Meada"), quebrar ("Ludismo"), cavar ("Mãos"), desfazer ("Salto"), desarmar ("Laboratório"), tatear ("Tato"), entre outras formas do desfazimento proposto.(BUCIOLI, 2003, p.48).

$\mathrm{O}$ ato de destruir interliga-se àquela consciência corrosiva, lucífera, que delineia o ato reflexivo da lírica de Fontela. Há por detrás desse ato de desconstrução a consciência plena da efemeridade da vida. Tudo se desfaz rumo à morte, em direção ao nada. Eis porque esse ato de destecer os fios da linguagem toma vulto na poesia orideana, ele é o emblema vivo dessa consciência extremada e iluminada ante a condição do homem. Em "Elegia (I)", o pasmo em relação à ausência da vida está marcado por essa desconstrução. A surpresa reside nessa falta de sentido que leva a totalidade da vida rumo ao caos da inexistência. 


\section{O pantempo}

A partir do verso doze, estendendo-se até o dezessete, o início da vida, marcado pela presença da infância, passa a pontuar o olhar que se dirige rumo ao fím da existência. Os fios opostos de uma trama, vida e morte, comunicam-se, formando assim uma espécie de círculo representativo da vida humana, em que o fim se liga ao início, e o princípio de tudo ao fim. Junqueira chama a atenção para a mistura temporal que marca o início do poema "Four quarterts" de Eliot. De acordo com o poeta brasileiro, nesse poema de Eliot, o passado, o presente e o futuro embaralham-se, quebrando a linearidade cronológica da existência. Tem-se, dessa forma, no poema de Eliot, aquilo que Junqueira (1998, p.84) chamou de "pantempo". O "pantempo" seria um momento totalizador, em que se aglutinam, em um único bloco, as sequiências temporais: futuropresente-passado. Evidentemente, o "pantempo" não acontece na realidade objetiva, mas sim na imaginação lírica. Trata-se de um mito poético capaz de aliviar a angústia ante a finitude humana. Eis o início do poema de Eliot, na tradução de Junqueira: "O tempo presente e o tempo passado/ Estão ambos talvez presentes no tempo futuro/E o tempo futuro contido no tempo passado." (ELIOT, 2000, p.199).

Assim, no poema de Fontela, a "criança que tateia/ no pássaro um esquema/ de distâncias" utiliza desse "pantempo" com o intuito de desconstruir, destecer a própria morte. Esse momento de epifania totaliza o tempo, salvando o ser poético, momentaneamente, da dissolução da morte. A realidade dura e inegável da finitude humana é suavizada pelo ludismo infantil que capta a vida e a morte em um momento totalizador, em um instante de plenitude.

Dessa forma, o eu lírico possui um posicionamento ambíguo em relação ao instante do efêmero, pois ao mesmo tempo em que ele percebe a fugacidade da vida, a morte, ele também elabora a busca de um instante que se aloja para além da precariedade da existência. $\mathrm{O}$ eu poético empreende essa busca, utilizando-se da presença da infância, presença essa que marca um movimento em direção às origens da vida. Portanto, da mesma forma que o tempo presente revela a vida rumo à morte, esse mesmo tempo possibilita uma abertura para as origens do que existe, para o atemporal. 


\section{A idealidade vazia}

No poema de Orides, há a busca de uma transcendência que, no fundo, não possui sentido. Na lírica moderna, tal procura de uma vivência mística ficou conhecida como "idealidade vazia". Friedrich salienta, na lírica moderna, essa necessidade de uma transcendência vazia que caracteriza a poesia de Baudelaire. De acordo com o crítico, o intenso desejo de espiritualidade que compõe a obra do poeta francês não possui um fim definido. Esse movimento de ascensão, de busca por algo que possa dar sentido à vida, não tem valor. Trata-se, na verdade, de uma transcendência destituída de um sentido. Essa ascensão vazia, essa mística sem conteúdo, converte-se em um Nada absoluto, "mistério que gira em torno de si mesmo" (FRIEDRICH, 1991, 48-49).

No verso dezoito de "Elegia (I)", podemos constatar a presença dessa transcendência oca. Nesse verso temos, novamente, em uma última aparição, a pergunta que abre o poema. Entretanto, o enigma que antes se mantinha em aberto, na constante falta de uma resposta do sujeito poético, agora, enfim, é solucionado: "O pássaro não serve". Eis que com essa afirmação, a epifania esboçada na estrofe anterior, pela inserção da infância como busca da origem, como símbolo da renovação da existência, degrada-se. O impulso pelo sagrado perde-se em uma constatação pessimista em relação ao fim da vida, em uma constatação de que o existir se fragmenta no nada absoluto. Tem-se, assim, em "Elegia (I)", a presença dessa idealidade vazia que caracteriza a poesia de Baudelaire. O impulso místico, na verdade, é um movimento em direção ao caos total, um vôo que se perde no vazio.

Novamente temos a presença daquela verticalidade de fundo mítico. $\mathrm{O}$ vôo em direção às alturas do sagrado, em direção à transcendência da existência, despenca-se na constatação pessimista de que a vida não possui fundamento. Também, novamente, podemos observar que a desconstrução da morte passa a perder o efeito, a destruição que na verdade impera e dá o tom niilista ao texto, é a destruição da vida.

Do pássaro vivo restam apenas as "brandas asas" em um repouso absoluto. Assim, Fontela delineia em seu poema a contradição entre o sagrado e o profano, entre a totalidade e a ausência, entre a vida e a morte, entre o infinito e o contingente. Feixe de paradoxos delineado na imagem simples e poderosa de um pássaro morto, essa imagem 
serve como correlato do destino humano, precário, porém, talvez por isso mesmo, pleno em seu mágico e perecível fulgor.

\section{Referências}

ARRIGUCCI JÚNIOR, D. Humildade, paixão e morte: a poesia de Manuel Bandeira. 2.ed. São Paulo: Cia. das letras, 1999.

AUGRAS, M. O ser da compreensão: fenomenologia da situação de psicodiagnóstico. 3.ed. Petrópolis: Vozes, 1986.

BACHELARD, G. A poética do espaço. 5.ed. Tradução de Antonio de Pádua Danesi. São Paulo: Martins Fontes, 2000.

O ar e os sonhos: ensaios sobre a imaginação do movimento. 2.ed. Tradução de Antonio de Pádua Danesi. São Paulo: Martins Fontes, 2001.

BENJAMIM, W. Magia e técnica, arte e poética. 3.ed. São Paulo: Brasiliense, 1987 (v. I).

BUCIOLI, C. A. B. Entretecer e tramar uma teia poética: a poesia de Orides Fontela. São Paulo: Annablume, 2003.

COHEN, J. Estrutura da linguagem poética. São Paulo: Cultrix, 1974.

ELIOT, T. S. Poesia. 7.ed. Tradução, introdução e notas de Ivan Junqueira. Rio de Janeiro: Nova Fronteira, 2000.

FONTELA, O. Alba. São Paulo: Roswitha Kempf, 1983.

Teia. São Paulo: Geração, 1996.

Trevo: (1969 - 1988). São Paulo: Duas Cidades, 1988.

HAMILTON, E. Mitologia. São Paulo: Martins Fontes, 1992.

FRIEDRICH, H. Estrutura da lírica moderna. Tradução de Marise M. Curione e Dora Ferreira da Silva. São Paulo: Duas Cidades, 1991.

MOISÉS, M. Dicionário de termos literários. São Paulo: Cultrix, [s.d.]

PAES, J. P. Os perigos da poesia e outros ensaios. Rio de Janeiro: Topbooks, 1997.

STAIGER, E. Conceitos fundamentais da poética. Rio de Janeiro: Tempo Brasileiro, 1972.

1 Doutorando (USP). 